This is an accepted author manuscript" (AAM) (also known as the "author post-print")

\title{
Double gamers: academics between fields
}

\section{Cristina Costa}

School of Education, University of Strathclyde, Glasgow, UK

cristina.costa@strath.ac.uk

\section{School of Education,}

University of Strathclyde

Glasgow 
This is an accepted author manuscript" (AAM) (also known as the "author post-print")

\section{Double gamers: academics between fields}

The field of academia is frequently associated with traditional norms that aim to regulate scholarly activity, especially research. The social web, as another field, is often viewed as challenging long-established conventions with novel knowledge production practices. Hence, the two fields seem to oppose rather than complement each other.

Using a Bourdieuian lens, this research examines research participants' accounts of their approaches to practice on the social web in relation to academia. The paper reports on the habitus dissonance between the two fields, before discussing the effects of the two fields' competing doxas on individuals' habitus.

Keywords: digital scholarship, doxa, symbolic violence, Pierre Bourdieu, the social web,

\section{Introduction}

Scholarship practices supported by the social web have received considerable attention in the last few years as a form of initiating academia into the digital economy (see, for example, the work of Weller, 2011; Veletsianos, 2012; 2013). Funding bodies such as JISC ${ }^{1}$, Research Councils UK and the European Commission have financed the development of virtual research environments, digital laboratories and knowledge networks to combine scholarly work with contemporary technological developments and related practices, especially those associated with the social web. For the purpose of this paper, the social web is understood as online networks, applications and 
This is an accepted author manuscript" (AAM) (also known as the "author post-print")

environments through which individuals communicate, socialise, and participate in knowledge networks and learning communities. The combination of scholarship and the social web suggests new forms of conducting practice (Wenger et al, 2010), learning and networking (Mason and Rennie, 2007; 2008). It offers new opportunities for collective work (Eysenbach, 2008; Hemmi et al, 2009; Rhoades et al, 2009) and distributed partnerships on a wider scale (Mcloughlin and Lee, 2007). It is also said to deliver ownership and autonomy to the individual as it yields a greater degree of control to the single user as a participant in a wider social environment (Franklin and Harmelen, 2008). But this type of autonomy has a price. The social web produces different forms of agency and power relationships (Jarrett, 2008). It has the potential to empower people but also to create new silos, as varying access to these new forms of working and communicating may well widen the digital divide gap and thus create new forms of inequality (Naughton, 2012) between those who have access and are prepared to adopt the social web and those who do not and/or are not.

However, the benefits of digital scholarship are not always perceived by academics (Greenhow et al, 2009; Xia, 2010) nor are they, for that matter, recognised by their institutions. And although there is an increasing movement in this direction, its influence is still minimal (Nichols, 2009) as opposition to it can still be strong. Many scholarly practices are the legacy of their historical past (Becher, 1994; Kemp and Jones, 2007), but also of their disciplinary nature (Whitley, 2000). They become accepted norms that are inculcated in scholars from generation to generation, and which are reflected in the main appraisal and reward systems that are in place. These 
This is an accepted author manuscript" (AAM) (also known as the "author post-print")

systems are likely to influence academics' attitudes toward change, innovation, and to a certain extent, risk taking (Williams, 2001).

In this vein, it is also important to consider the current global economic crisis from which the academic world is not exempt. Budget cuts across the education sector inevitably compromise existing practices and may well jeopardise different forms of work innovation, considering the priority given to securing funding and increasing or maintaining academic prestige through benchmarks that have proven successful in the past (Lee, 2007).

At the time this research was conducted, Higher Education Institutions (HEIs) in the UK were preparing for the Research Excellence Framework (REF), a national research assessment that stipulates the research funding allocated to each institution. Yet the pressure to acquire funding via exercises that vouch for the quality of the research conducted in HEls is not unique to the UK. Countries such as Australia, New Zealand, Spain and South Africa also have their own mechanisms to assess the quality of research, mainly through the number of publications and the ranking of the journals in which academic work is published (Williams, 1998; Talib, 1999, 2001, 2003; Bence and Oppenheim, 2004). Smith et al (2011) reflect on the threats such exercises pose to academic autonomy given the narrow notions of impact stipulated by research evaluation committees and interpreted by institutional leaders. The Research Excellence Framework in the UK is a good example of this. Bence and Oppenheim (2004) assert that such exercises 'distort the patterns of academic publishing' (p.64). They also stifle innovation (Lucas, 2006) and 'damage scholarship' (Williams, 1998, 
This is an accepted author manuscript" (AAM) (also known as the "author post-print")

p.1081). National research evaluations lead institutions and individuals alike to devise strategies regarding what and where to publish (Talib, 2001; Wellington and Torgeson, 2005; Northcott and Linacre, 2010) instead of seeking alternative channels to extend their influence to different audiences and/or exploit different forms of impact that are congruent with the needs of a society that more and more relies on technologies to communicate and access information. In short, such exercises inevitably tend to lead to a change of publishing behaviour in favour of funding (Butler, 2003). Moreover, such evaluations institutionalise research activity (Holligan, 2011) as an exercise that aims to generate funding for institutions rather than promote new knowledge and debate.

There is no doubt that for academia the social web provides alternative conduits for the creation, communication and publication of scholarly work (Weller, 2011). As such, practices on the web are starting to encourage individuals to question established norms and adopt new philosophies of practice that challenge conventions implicit in academic work. This can be illustrated, for instance, via current debates and practices regarding open access publications (Björk, 2004; Swan, 2010; Laakso et al, 2011) or the use of blogs as a platform for the communication of research (Pearce et al, 2011). This facet of the social web, as an agent of change and innovation, has been well documented in the literature (see the work of Conole, 2004; Veletsianos, 2010, 2012; Weller 2011). However, the available body of knowledge presents a number of gaps pertaining to the link between theory and practice when embedding the social web in one's scholarly practice. This gap also includes the absence of the voices of those who advocate the active use of the social web for research purposes as the 
This is an accepted author manuscript" (AAM) (also known as the "author post-print")

majority of the knowledge published so far focuses mainly on learning and teaching (--$---, 2011)$ as an element of scholarly work (Boyer, 1997).

This paper provides a fresh and critical interpretation of the research practices supported by academia and those developed on the social web in the contexts of the current economic crisis, the research assessment exercises that measure and regulate institutions' research excellence nationally and internationally, and the technological developments that inevitably impact on knowledge work activities. Drawing on Bourdieu's thinking tools, namely, field, habitus, (forms of) capital, symbolic violence and doxa, the analysis of this paper focuses on the perceptions of academic researchers who are actively engaged in digital scholarship practices. Digital scholars are herein understood as academic members of staff who engage in digital scholarship practices. i.e., scholarly activities that are supported and enhanced by the social web and, especially, the movements and ideals associated with it. In this paper, digital scholarship practices are also understood as having strong roots in a culture of sharing, openness and transparency. As such, engagement in environments, activities, and networks sustained by the social web makes scholars more than users of the web; it changes their mindsets as well as their social and cultural capital (See ------, 2014). They not only use the web as knowledge consumers, but also as knowledge producers and self-publishers, participants in online knowledge networks, and advocates of academic change with the support of the social web.

The research aims to contribute to the debate surrounding the implications of adopting digital scholarly practices by academics. Through research participants' 
This is an accepted author manuscript" (AAM) (also known as the "author post-print")

accounts, this paper reports on how HEls exercise symbolic violence to preserve or augment their symbolic capital, before discussing how doxa is also present on the social web and how it affects research participants' academic habitus. This research uses Bourdieu's key thinking tools to analyse the effects of the interplay between the two fields and their competing doxas in relation to research participants' habitus. The result is an academic habitus 'at crossroads' that leads research participants to devise a strategy that allows them to keep their player status in both fields.

\section{Research Lens: The field of academia and its digital players}

Bourdieu's key concepts of field, habitus, (forms of) capital, symbolic violence and doxa are applied to this research as both a theoretical lens and a method through which the phenomenon under study can be understood and explained without losing sight of the multi-layered social milieu in which it is inserted. Key to Bourdieu's research is the interdependence between the 'objective social world' (Jenkins, 2002, p.25), such as institutions and organisations, and the subjectivity the social agents bring to that social world, i.e., their dispositions that translate into practices that reproduce and/or oppose the norms of the social space.

Using the concept of field in this paper means to consider academia and the social web as social spaces to which research participants belong as social agents. Compared to a game, field works 'in terms of relations' (Bourdieu and Wacquant, 1992, p. 96), and is therefore understood in interdependence with the forms of capital 
This is an accepted author manuscript" (AAM) (also known as the "author post-print") and habitus that the different agents bring into the social spaces in which they interact. Fields as spaces of struggle have 'their own rules, histories, star players, legends and lore' (Thomson, 2008, p.69). Field is also perceived in relation to the positions agents occupy in a social space and the rules associated with those positions. As such, each field presents a specific structure in which social agents interact, compete and/or strive for forms of capital valued by that particular field. This makes field a non-static structure as it is always in direct and causal relationship with the habitus that agents, who interact in that social space, exhibit.

Bourdieu uses habitus to explain how individuals act, think, perceive and approach the world and their role in a given field. Habitus, as a set of individual and shared 'structured, structuring dispositions' (Bourdieu, 1990, p.52) developed in practice, presents and justifies individuals' perspectives, values and actions in relation to the social spaces in which they co-exist. Depending on what is at stake, individual habitus can agree, conflict, or compromise with the field.

In elaborating on the contrast between research participants' scholarship habitus - which is influenced by their active engagement on the social web (------, 2014) - and their understanding of the field's expectations - which is perceived as having a more cautious view of the role of the social web in supporting scholarly work - it is important to draw on the concept of capital. Bourdieu (1985) identified four different types of capital: economic, social, cultural and symbolic. Forms of capital have a direct influence on both the habitus and the field. However, depending on what is to be won or lost, different forms of capital may weigh more, or less, when influencing the 
This is an accepted author manuscript" (AAM) (also known as the "author post-print")

habitus and the field. For instance, individuals' digital social capital, i.e, their networks and learning communities online, may influence their approach to digital scholarship practices (see ------, 2014), as they share similar values and practices, i.e, embodied cultural capital. Symbolic capital, translated into forms of prestige and distinction, and economic capital may, however, play a more visible role in influencing the field of academia as HEls continually strive to achieve, maintain and increase their reputation in the national and international HE ranks. This becomes an even more important goal for academia given the benchmarks against which they are compared, as well as the current global economic crisis that challenges their trade.

Also important to this research are the concepts of symbolic violence and doxa. Symbolic violence -the authority that fields convey based on the power mechanisms they possess (Bourdieu and Passeron, 1990, p.4) - is present in the whole of the social space (Bourdieu, 1980). Every individual is able to recognise his/her role in the field in relation to the norms of the dominant 'forces'. These silent cues can, and often do, condition one's dispositions to practice. Bourdieu calls these hidden rules the field of doxa (Bourdieu, 1972, p.169) that eventually becomes a collective belief with which social agents are expected to comply as they take the field's structure for granted (Bourdieu, 1998, p.242). Symbolic violence and doxa are key tools in understanding how research participants' perceptions of the field conflict with their scholarly habitus and the impact it has on their practices. Bourdieu claims that the interdependence between field, habitus, and forms of capital result in a given logic of practice (Bourdieu, 1990). This research suggests that symbolic violence and doxa are no less important in recognising how the logic of practice is imposed and/or questioned. 
This is an accepted author manuscript" (AAM) (also known as the "author post-print")

Bourdieu's key concepts 'provide a method for developing [an analysis] that reflects the complexities of the contemporary social world' (Reay, 1995, p.231) in which research participants' scholarly practice takes place. Moreover, Bourdieu's work can be used as a both method and theory (Wacquant, 2013; 2014). Bourdieu's thinking tools have also informed this research in that they surpass the dichotomy between practice and theory by combining both. Thus, in using Bourdieu's thinking tools, this article aims to answer the following questions:

-How do academic researchers who are involved in digital scholarship practices, i.e, digital scholars, perceive the field of academia?

-To what extent do the scholarly habitus of research participants conflict with the rules of the field and vice-versa?

\section{The study}

This study explores the perceptions of ten academic researchers regarding their active involvement in digital scholarship practices and the challenges they face when embracing digital scholarship practices in the current socio-economic and academic contexts.

For the purposes of this project, research, as an element of scholarship (Boyer, 1997), is the focus of the paper. Research participants were recruited following a purposive sampling technique, as it lends itself to 'selecting information-rich cases for study in depth'"' (Patton, 1990, p. 169). This technique allowed the researcher to work 
This is an accepted author manuscript" (AAM) (also known as the "author post-print")

with research participants who featured given characteristics that make them a representative group (Topp et al, 2004) of academic researchers engaged in digital scholarship practices.

The selection criteria designated for this study meant that research participants:

-were active researchers in an academic setting, i.e, had research time allocated to their workload as part of their academic contract -used the social web in a proactive way as part of their professional activity.

-had an active web presence online, which was stipulated by their active participation in social network sites and use of communication tools for professional purposes, such as Twitter, personal and collective blogs, etc.

Of the ten research participants involved in this study, four were women and six were men. Given that gender issues did not arise through research participants' accounts and this was not the main focus of the research, such aspects are not explored in this article.

The study is based on a narrative inquiry approach as it suits well the purpose of studying practice (Schwab, 1960). The collection and analysis of data followed an iterative process that included the involvement of the research participants as both narrators and interpreters of their experiences in two distinct stages of the research process: first, as they constructed their narratives of practices by participating in the research interviews (Conle, 2000), and second as they took a second 'interpretative 
This is an accepted author manuscript" (AAM) (also known as the "author post-print")

stance toward their data' (Conle, 2010, p. 156) by also reading and approving or enhancing my first pass at writing and interpreting their narratives.

The interviews, which were audio recorded and later transcribed, followed a loose guide of topics related to participants' research practice in order to promote a spontaneous pattern of conversation and 'clarify lived values' (Conle, 2010, p.157) shared by the research participants with regards to their digital scholarship practices. It also aimed to make research participants the main actors of the research interviews and thus give them ownership of their narratives of practice without losing sight of the purpose of this research. This allowed me to elicit research participants' own experiences and perspectives through their own accounts (Bruner, 1991; Clandinin and Connelly, 1989; Clandinin, 2006; Riessman, 2007), and consequently identify the perceived conflicts and constraints research participants face as digital scholars and which this paper seeks to tease out.

Additional forms of data collection were also employed in order to construct a richer picture of the research narratives. These included field notes that I collected during and right after the research interviews took place. The field notes recorded research participants' reactions to the research interview questions. This highlighted the emphasis they put on the values they shared about the digital scholarship practices they actively supported, endorsed, and to some extent participated in. Comments generated from post-interview interactions between the research participants and I also constituted valuable research data, as research participants were given access to 
This is an accepted author manuscript" (AAM) (also known as the "author post-print")

my first interpretation of their narratives of practices and the possibility to comment on it as a form of making the research process an inclusive and interactive process.

The research data were coded and analysed thematically with Bourdieu's key concepts supplying a method of analysis of research participants' narrated interpretations of lived experiences and values enclosed in the social, cultural, historical, economic, and political spaces of academia and the social web.

The sections that follow present the analysis of the research through Bourdieu's thinking tools. The research findings unveiled the conflicts between institutional expectations and individuals' practices and stressed the tensions between personal and institutional goals.

\section{The field of academic research}

The research narratives featuring in this study demonstrate that academic research, as a sub-field of academia, is currently dominated by the rules and structures that rate and regulate academic research practice not only locally, but also nationally and internationally.

The participants of this study, who are social agents in the field of academia, report on the contrast between their academic dispositions (that lean towards digital scholarship practices) and expected forms of production of academic work, in 
This is an accepted author manuscript" (AAM) (also known as the "author post-print")

particular research. Research participants perceive the field as restrictive of their creative and innovative input:

There has been a tension between the institutional expectation of what I should be doing and what I should be producing - that is a research monograph on one particular topic - and where my intellectual journey is taking me, which is somewhere that is a lot more fascinating (...) intellectually, something that is a lot more timely. (John)

This is especially felt in the context of the expectations that are put on research participants regarding the dissemination of research findings. This tension becomes even more evident when the institution implicitly and explicitly imposes guidelines to scholarly activity that lead to the standardisation of their practice:

That's basically what they do [write papers and present at conferences]. (...) I think that that's still what's valued, and it's that sort of thing that's recognised and viewed as important. (Alex)

You are very constrained by what the university expects of you, in terms of you can't get promotion unless you've got 5 articles in a peer reviewed journal. (Lucy)

Whereas institutions tend to support the communication of research through conventional outlets such as toll access journal articles, as reported in participants' narratives, scholars actively engaged in the social web tend to adopt practices such as open access ${ }^{2}$ publications that may conflict with those endorsed by the institution. The social web exposes individuals to other forms of communication and the dissemination of knowledge that the field of academia has not yet officially recognised and valued, 
This is an accepted author manuscript" (AAM) (also known as the "author post-print")

because of its less established reputation, and which in return - it could be argued does not meet the ambitions of academia in acquiring symbolic capital. Digital scholarship practices, as defined in this research (and depicted in another publication), transform scholarly habitus (see ------, 2014). This difference between agents' dispositions and the structures in which they officially operate 'expresses itself both in directly economic and political antagonisms and in a system of symbolic positions and oppositions' (Bourdieu and Passeron, 1977, p.204).

It is also interesting to note the message institutions allegedly send to their researchers regarding their internal research goals and strategies. According to research participants, judgment on the quality of research seems directly correlated with the impact factor of the journals in which research is published rather than the content of the research itself:

The University is completely hung up on impact factor as a means of measuring the research, because it has such great importance in the REF. Things like conferences and publishing in open access, but not impact factor journals - has no institutional recognition. Really the only thing that counts at the present time here is grant income and impact factor. (Hector)

Academic institutions as fields of power follow rules (Bourdieu and Wacquant, 1992, p. 98) that aim to set a structure for agents' actions. In doing so, it creates internal norms that aim to ensure the reproduction of their institutional culture. This is particularly evident in the accounts research participants give of the messages their institutions send regarding the types of research outputs they expect to be produced as well as the location of where such outputs are supposed to be published. This is 
This is an accepted author manuscript" (AAM) (also known as the "author post-print")

particularly curious in the case of the UK, given that, as the Minister for Universities and Science in the UK came to announce, REF guidelines focus on the quality of publications rather than on the publisher (Willetts, 2011) . $^{3}$

Even though in the majority of the cases analysed, the national research exercises do not specify where research should be published, institutions have reportedly developed their own regulations regarding how they measure their research capacity internally in order to ensure that their economic and symbolic capital is not compromised. In light of the global economic crisis, this kind of institutional pressure is higher given that research funding is even scarcer. Therefore, the need for maintaining and/or increasing institutional reputation and prestige is greater.

Institutional rules are created to support and promote the aspirations of the field. Bourdieu calls these institutional rules the field of doxa (Bourdieu, 1972, p.169) that eventually becomes a collective belief with which social agents are asked to comply. Doxa is thus a form of domination; of symbolic violence. In the case of research participants' reported experiences, symbolic violence is revealed through the "orthodoxies" institutions seem to create with regards to research publications in an attempt to regulate research practice and reproduce the field's expectations and goals in accumulating symbolic capital and symbolic power:

[Research exercises] have such a corrosive impact on practice, because certainly here we're just completely obsessed with impact factors as the only way of measuring research output effectively. (Hector) 
This is an accepted author manuscript" (AAM) (also known as the "author post-print")

I can say I wrote 15 blogposts and my wiki has grown exponentially and I'm having all this great conversation with people and I'm learning a lot, and they're like 'ermmmmm', so. Unless I'm producing output in a format that the university values they don't look at what I'm doing as research. (Luke)

Symbolic violence is effective when the dominating culture is imposed upon people and experienced as the legitimate one (Green, 2013). This is clearly expressed in the narratives collected for this research, as the citation-example below illustrates:

It's [using participatory media] not playing safe (...). I actually didn't blog at all about historical research or geopolitics, because I felt it would not be well accepted. (John)

Participants report about feeling limited to research practices that no longer match their epistemologies of practice, i.e., the ideals and practices that typify research participants' beliefs and values with regards to their professional activity. Their interaction with the social web, and the groups with which they congregate therein, present research participants with new forms of working and thinking which inevitably inform their practice tendencies, and thus their academic habitus (see ------, 2014). For example, research participants' exposure to and participation in the Open Access movement transform their views of scholarship regarding where and how they wish to publish their research outputs. Yet, institutions may share a different approach with regards to where researchers should publish their academic work. To achieve its goals, the field promotes doxic thinking in order to exercise control over the social agents that perform within the sphere of the field. In doing so, it seeks to strengthen its position and maintain its power. As a result, participants, as social agents in both 
This is an accepted author manuscript" (AAM) (also known as the "author post-print")

the fields of academia and the social web, face the internal conflict between keeping a relevant position in their institutions and following their evolving approaches to practice, that have been informed by their participation on the social web. This is, for instance, exemplified by the decisions research participants have to make regarding the publication of research outputs:

Many of the places that I'd actually like to publish my research - many of the open access journals no impact factor. So anything that I publish in [an open access journal] from the University's point of view doesn't count as research activity. (...) I am viewed - and this phrase has been used - I am viewed as a problem, because I'm not included. I'm a member of academic staff, but I'm not included in the REF. (Hector)

If I publish that article in an open access journal... there are very few accredited open access journals, so the University won't recognise my publication. So there's absolutely no incentive for me to publish in an open access journal (Luke)

Research participants must decide between attempting to publish their research in prestigious journals that follow closed publishing conventions or making their work accessible via Open Access journals and alternative publishing practices; an approach that matches their dispositions towards digital scholarship practices, but which contrasts with the aspirations of their institutions. The more research practice is regulated - as is the case with the dissemination of research - the more research participants feel torn between structure and agency, i.e., between field and habitus. The more the field reproduces itself into individuals' dispositions, the less scope it presents for innovative and creative practice. As Bourdieu (1998) reminds us:

'The professionalization [of academics] and the conditions required of those who want to make a 
This is an accepted author manuscript" (AAM) (also known as the "author post-print")

career in [academia] increasingly exclude inspired personalities' (p.5).

Research participants' accounts suggest that the doxic standpoint displayed by the field of academia can stifle innovation regarding the way academics support, promote and/or extend their scholarly work given that it does not provide a conducive environment for different or alternative forms of scholarly work, nor does it seem to officially support practices that lie outside the immediate goals of the field of academia:

What you get rewarded for are journal articles and traditional metrics, so the message often to young researchers is not to bother with all this sort of stuff, that it's a waste of time. (Alex)

The rules of the field, felt as a form of opposition to research participants' trajectories on the web, can also be interpreted in relation to their position in the field of academia. The higher research participants seem to be placed in institution hierarchy, the less conflict they seem to experience at a personal level:

I can pick and choose what I do. I can play the university game if I want to, but if I don't want to I don't have to. Career-wise I can make that choice. But people who maybe are just setting out in their career and they're trying to build a career path as a researcher in a university are very constrained by what the university expects them (Lucy)

I'm also lucky in that I was already a professor when I got into blogging, I've got room to play and explore with my career. I'm in the reasonably privileged position of not having to seek promotion.(...) I too feel the pressure and I am trying to play both games (Richard) 
This is an accepted author manuscript" (AAM) (also known as the "author post-print")

The notion of power herein reported in relation to their career stages - their position in the academic hierarchy - and their academic ambitions is however relative, as academics are bound by a set of rules that regulate academic practice. Hence, the perceived power each individual may have in the field is arguably more directly related to their individual condition (career stages and aspirations, for instance) rather than collective practice. In this sense, their position in the field seems to be more efficient in affecting their individual practice than triggering immediate change in the field:

In almost any other industry, your new blood that comes in are the people that bring all the innovation and change, whereas when we bring our new blood in academia we deliberately say to them, don't engage with any of this new stuff, don't try and change practice, because you won't get recognised, you won't get promoted, so we make them very conservative. (Richard)

This perception is also shared by those who have a relatively less powerful position in the field:

To get a permanent position in the university, I need to get credibility, and to get credibility you have to have papers in journals with impact in the citation index. (Maria)

Nonetheless, the cases of practice investigated in this research project show that cross-field effects (Lingard and Rawolle, 2004) can also happen. No field is static and the confluence of habitus from different social fields can encourage changes of practice through the influence one field exerts on another. In this sense, the doxa typical of one field can be questioned and can thus lead to changes in another field. Yet, changes in the field can only be conducted by its social agents insofar as they manage to remain relevant in the field they aim to change. In this sense, the participants featured in this study are also agents who aim to promote change by questioning and challenging the field's doxic thinking with their practices. 
This is an accepted author manuscript" (AAM) (also known as the "author post-print")

The next section will explore how participants, as supporters and users of the social web for scholarly work "play the game", i.e., engage in online practices that aim to push to boundaries of current academic conventions at the same time they attempt to remain relevant in the context of their institution.

\section{Playing the game: modes of domination versus acts of resistance}

In an attempt to ensure coherence and stability, the field devises mechanisms that aim at the reproduction of the social space it intends to create and maintain. In the case of HEls this is seen and felt through the norms and regulations that define academic researchers' practices, their positions and roles in the institution, and also their identity and reputation. The national research exercises can, in this context, be interpreted as mechanisms of symbolic violence that aim to reproduce the HEI's logic of practice. The same applies to the HEl's interpretations of such exercises and the strategies they develop internally as their response to maintaining or boosting their status quo. At stake is their position (of power) in the HEl's hierarchy. Hence, the more effective those mechanisms are in ensuring the (re)production of symbolic capital, the more successful the field is in shaping social agents' dispositions, and 'the greater is the field of doxa' (Bourdieu, 1977, p.166). Yet, domination does not occur in a linear or predictable fashion. Field, as an objective structure, is not totally opaque to change and influence. Social agents' habitus can have an impact on the field too, because as 
This is an accepted author manuscript" (AAM) (also known as the "author post-print")

Wacquant contends, habitus, as a container of social action, can indeed be a source of creative development (2014).

Research participants in this study demonstrated through their narratives of practice that they have developed an academic habitus - through interaction in another field, that of the social web - that may divert them from fulfilling the expectations of the field of academia, especially with regards to the dissemination of research:

I split it [my activity] into formal and informal. In the formal track I make sure I am keeping up with the expectations of the university and what they expect from me, and then my informal track is everything else. (Luke)

The academic habitus of research participants can be attributed to their participation in the social web and exposure to practices that take place therein and which differ from those they traditionally encounter in their workplaces. Research participants' engagement in the social web results in approaches to practice that tend to satisfy the interests they share within their distributed online networks rather than replicating the expectations of the field of academia. The field of academia may, in this case, be less effective in configuring research participants' dispositions because their online social capital plays a supportive role in shaping their academic habitus (See ----------, 2014). Nonetheless, research participants also showed 'a feel for the game' (Bourdieu, 1998, p.25), i.e., awareness of their need to remain relevant in their institution, as a form of promoting change at the same time they push the boundaries through their active use of the social web for scholarly purposes: 
This is an accepted author manuscript" (AAM) (also known as the "author post-print")

In my case I have to make this kind of double game to survive here, because if I don't stay in academia I cannot make different things. So I want to get my position, my permanent position, and then start deciding what I want to do, and for what I want to write. (Maria)

I do feel that pressure and I'm trying to play both games, so l've not completely stopped publishing, so I'll try and do enough publications to meet the REF requirements (Richard)

The analysis of the research narratives reveals that research participants are aware of the barriers and implications of adopting research practices supported by the social web. The field of academia exerts power over agency in order to ensure the stability of its structure. Individuals cannot overcome this opposite force on their own, because:

There exist relatively autonomous fields [that], functioning in accordance with rigorous mechanisms capable of imposing their necessity on the agents (...) [aim] at the domination of individuals, a domination which in this case is the condition of the appropriation of the material and symbolic profits of their labour (Bourdieu, 1977, p.184).

Academia relies on academics' research outputs to preserve and/or increase the prestige of its research institutions. This is not only a core condition of its existence, but also a key feature of academic researchers' roles and activities. In this context, this leads participants to take a strategic approach as to how they combine conventional and innovative research practices, i.e., how they comply with the rules of the field of academia without losing sight of the practices supported by the social web towards which their dispositions lean. In this sense, many of the research participants 
This is an accepted author manuscript" (AAM) (also known as the "author post-print")

explicitly defined themselves or hinted at their approach as 'double gamers' or individuals who 'play the game'; a strategy that allows participants to slowly implement cultural changes to practice while they manage to remain relevant within their institution so that they can be the catalysts of that change. In other words, being a 'double gamer' implies following some of the rules of the field of academia, as the environments and practices they encounter within the social web are 'too different from the one to which they are objectively adjusted' (Bourdieu, 1990, p.62), without losing sight of the future developments with regards to knowledge production in the digital economy.

Research participants' academic habitus is thus driven by their online social capital and justified by their participation in the social web, but moderated by the field of academia in which their scholarly practices take place and are recognised and validated. The interplay between habitus, field and capital, 'orients [research participants'] playing strategies' (Bourdieu, 2000, p.215).

The exercise of symbolic violence by the field of academia is thus justified by its need to dominate, maintain, or restore power to its structure. Symbolic violence is utilised as an invisible mechanism of coercion by institutions that use research assessments exercises as a pretext to regulate research practice internally. In this process of exerting power, individuals are reminded of their roles in the field of academia. As a result, the dispositions they acquired on the social web might be affected. As Bourdieu (1990) asserts 
This is an accepted author manuscript" (AAM) (also known as the "author post-print")

Strategies aimed at producing practice according

to the rules are one among other type of

officialization strategy, aimed at transmuting

"egoistic", private particular interests (notions

which can only be defined in the relationship

between a social unit and the unit which

encompasses it at the higher level) into

"disinterested", collective, publicly avowable, legitimate interests (p.109).

Bourdieu (1977) also conceptualises symbolic violence in the context of

different forms of capital that can be translated into symbols of prestige (p.180).

Participants of this study suggest that expectations of the institution regarding their

research practice and derived outputs are more directed at acquisition of funding and

success in the national research assessment exercises than on the development of new

knowledge and recognition of new approaches to research practice, as illustrated

below:

(...) someone that I highly regard, as a leader in this field that we're in... hasn't been able to get promotion, or a pay rise or something because the university research expectations ... that just illustrates the power of the university. To be fair, it's not just universities, it's governments saying we'll fund you if you've got $x$ amount of journal articles. So while you don't want to play that game, and you want to push the boundaries, and you want the universities to think about alternative ways of doing things... at the same time you've got to pay the mortgage, haven't you? So it's very tricky. But I think things are changing. (Lucy)

For the research participants this represents a clash with their ideals, values and purposes of engaging in scholarship practices in the context of the digital economy. The tension between institutions' research expectations and participants' 
This is an accepted author manuscript" (AAM) (also known as the "author post-print")

scholarly approaches results in a digital dissonance between field and habitus. This digital dissonance in not in relation to the accessibility to digital technologies, but rather to epistemologies of practice that are developed online and which aim to transform more conventional forms of scholarly work. What this dissonance provides is an opportunity for cross-field effects in which the influence of one field in exerted onto the other (Rawolle and Lingard, 2008).

\section{Discussion and Conclusions - double gamers: academics between fields}

This paper aimed to interpret research participants' perceptions of their digital scholarly practices in relation to the fields that validate and produce them, i.e., academia and the social web respectively. Using Bourdieu's key concepts as a research lens, this research depicted two contrasting pictures with regards to research participants' approaches to scholarly practices. Institutions and research participants tend to take separate views on how research practice should be conducted, and especially where research should be published. Whereas HEls reportedly support and reward the publication of research via formal channels, with a special emphasis on high impact journals that follow toll access publication conventions, research participants tend or would prefer -when given the choice - to publish their research in open access journals or use alternative forms of research communication such as blogs. This reveals not only a tension between structure and agency (field and habitus), but also a disagreement between two distinct fields with social agents in common. The result is the adoption of a dual habitus that allows research participants to keep their 
This is an accepted author manuscript" (AAM) (also known as the "author post-print")

'player status' in both fields, while they attempt to change the habitus of academia with the habitus they acquired on the social web.

It could be argued that, if academia, as a field, exerts symbolic violence to impose a given scholarly culture, the social web, as a parallel field in which research participants interact, is no less powerful in promoting firm, yet contradicting, assumptions of how scholarship should be practised. In doing so, both fields implicitly seek to ensure social agents' 'undisputable, pre-reflexive, naïve, native compliance with the fundamental presuppositions of the field which is the very definition of doxa' (Bourdieu, 1990, p.68). Social agents' participation across fields can however 'corrupt' naïve compliance with the rules of one field by virtue of being influenced by the rules of another field. Seen from this perspective, doxa can unexpectedly have a dual effect in that, depending on the field that creates it and the field to which it is applied, it can be used as a form of domination and/or a form of (de)liberation.

Taking the current research, as an example, it is possible to assert that both the fields of academia and the social web share assumptions that are "based on "collective expectations" or socially inculcated beliefs' (Bourdieu, 1998a, p.103) as a form of justifying their standpoints and thus shaping the habitus of their members. This is noticeable in research participants' accounts of how they - influenced by their experiences on the social web - advocate digital scholarly practices and oppose research practices that academia allegedly tries to impose on them. With social players commuting between fields with competing doxas, the doxa of one field can be transported to another field through social agents' habitus. This opens up an opportunity for cross-field effects (Lingard and Rawolle, 2004; Rawolle, 2005; Rawolle and Lingard, 2008), in that the doxa that in one field is a force of domination can be 
This is an accepted author manuscript" (AAM) (also known as the "author post-print")

used in another field as a form of contesting the established order. In this sense, doxa can be approached as a tool of change. This is possible because social agents, as players in different fields can question the presuppositions of a given field with the practices developed in another field. In doing so, they challenge the institutionalised habitus with the suggestion of another habitus. This can lead to conflicts; clashes between accepted and proposed habitus that aim to lead to the transformation of the social field, as this research depicted. Habitus can thus been regarded as a 'generative and unifying power' (Wacquant, 2013, p.3) capable of creating cross-field effects as it transported from one field to another by social agents.

As Bourdieu reminds us 'what is at stake here is the power of imposing a vision of the social world' (Bourdieu, 1991, p. 221) in the hope of preserving or changing social agents' habitus as field. Doxa is often regarded as a mechanism of field domination (Bourdieu and Passeron, 1990); yet when transported from one field to the other through social agents' habitus it can induce social agents to question the structure of the field and the habitus therein proclaimed. This research acknowledges that habitus, as a social construct, has often been criticised for being deterministic (see, for example King, 2000). This research aims to demonstrate that, although habitus may well be 'durable (...) it is not eternal' (Bourdieu and Wacquant $1992 \mathrm{p}$. 133). This is not to say that fields are spaces of constant change and mutability either. Nonetheless, no social field is completely static, and even fields enjoying long established traditions are not impervious to change, as the need to adapt to a changing society becomes an imperative when trying to maintain its significance in relation to other social fields. 
This is an accepted author manuscript" (AAM) (also known as the "author post-print")

The dialectics between fields with competing doxas can lead to the questioning of practices in one field via the habitus social agents develop in other fields. In the case of this research this is illustrated through the disagreement with the rules of academia by virtue of the practices developed on the social web. In this sense, the doxa that is used as a mechanism of domination in one field can be seen as a potential catalyst of change in another field through the questions it evokes. Nonetheless, change can only occur insofar as the new proposed practices are accepted as the new collective habitus of the field in which the doxic approach - borrowed from a competing field - manages to impose itself as the norm, i.e., as the new doxa of the field.

Referring back to the research presented in this paper, and notwithstanding the opposition between the two fields, the academic field seems to be more effective in reproducing its logic of practice and making its agents play by their rules, because of the symbolic capital it possesses, and which determines the power of the field over its agents (Bourdieu, 2004, p.34). This can be ascribed to two factors. First, academia as a field enjoys long-established conventions to which a majority of its social players still seem to subscribe as their adopted academic habitus. In contrast, the history of the social web is still in its infancy, making it harder to convert the practices it supports into established norms. The durability of the academic habitus becomes a form of symbolic capital with which the social web cannot yet compete given the reputation and prestige enjoyed by the former in comparison with the latter. Second, academia as a field uses official channels and regulations to impose its goals. The social web operates on a more informal structure, in which participants' practices are not 
This is an accepted author manuscript" (AAM) (also known as the "author post-print")

prescribed, with the exception, of course, of the collective beliefs that are therein formed and shared. This leads social agents predisposed to digital scholarly practices to strategically adopt a dual habitus instead of rejecting one in favour of the other. Research participants' playing 'strategies are [thus] oriented by the objective constraints and [also by] possibilities implied in their respective position[s]' (Bourdieu, 2004, p.35) in both fields. This results in a 'double gamer' approach; a compromise that allows research participants to remain relevant in both fields while they attempt to change the academic practices of one field the activities developed in the other.

\section{References}

Becher, T. 1994 Academic Tribes and Territories: Intellectual Enquiry and the Cultures of Disciplines. 1st ed.

Bence, Valerie, and Charles Oppenheim. 2004. 'The Role of Academic Journal Publications in the UK Research Assessment Exercise'. Learned Publishing 17 (1): 53-68.

Björk, Bo-Christer. 2004. 'Open Access to Scientific Publications - An Analysis of the Barriers to Change?' https://helda.helsinki.fi/handle/10227/647.

Bourdieu, Pierre. 1977. Outline of a Theory of Practice. Cambridge University Press.

- - . 1984. Distinction: a social critique of the judgement of taste. London: Routledge. 
This is an accepted author manuscript" (AAM) (also known as the "author post-print")

- - . 1985. 'Forms of Capital'. In Handbook of Theory of Research for the Sociology of Education, 241-58. Greenwood Press.

- - . 1988. Homo Academicus. Stanford University Press.

- - . 1990. The Logic of Practice. Stanford University Press.

-- - 1991. Language and Symbolic Power. Harvard University Press.

- - 1998. Practical Reason: On the Theory of Action. Cambridge: Polity Press.

- - - 2004. Science of Science and Reflexivity. Cambridge: Polity.

Bourdieu, Pierre, and Jean-Claude Passeron. 1977. Reproduction in Education, Society and Culture. SAGE.

Bourdieu, Pierre, and Loïc J. D Wacquant,. 1992. An Invitation to Reflexive Sociology. Cambridge: Polity Press.

Boyer, Ernest L. 1997. Scholarship Reconsidered: Priorities of the Professoriate. Carnegie Foundation for the Advancement of Teaching.

Bruner, J. 1991. 'The Narrative Construction of Reality'. Critical Inquiry (18): 1-21. 
This is an accepted author manuscript" (AAM) (also known as the "author post-print")

Butler, Linda. 2003. 'Modifying Publication Practices in Response to Funding Formulas'. Research Evaluation 12 (1): 39-46.

Clandinin, D. Jean. 2006. 'Narrative Inquiry: A Methodology for Studying Lived Experience'. Research Studies in Music Education 27 (1): $44-54$.

Clandinin, D. Jean, and F. Michael Connelly. 1989. 'Narrative and Story in Practice and Research.' http://www.eric.ed.gov/ERICWebPortal/contentdelivery/servlet/ERICServlet?accno=E D309681.

Conle, Carola. 2000. 'Narrative Inquiry: Research Tool and Medium for Professional Development'. European Journal of Teacher Education 23 (1): 49-63.

- - . 2010. 'Practice and Theory of Narrative Inquiry in Education'. In Habermas, Critical Theory and Education, edited by Mark Murphy and Ted Fleming. London: Routledge.

Conole, Grainne. 2004. 'E-Learning: The Hype and the Reality'. Journal of Interactive Media in Education 11. http://www-jime.open.ac.uk/2004/12/.

Eysenbach, Gunther. 2008. 'Medicine 2.0: Social Networking, Collaboration, Participation, Apomediation, and Openness'. Journal of Medical Internet Research 10 (3). 
This is an accepted author manuscript" (AAM) (also known as the "author post-print")

- - 'The Open Access Advantage' 8 (2). doi:10.2196/jmir.8.2.e8.

Franklin, and M. Harmelen. 2007. 'Web 2.0 for Content for Learning and Teaching in Higher Education'. Teaching in Higher Education 2008 (May): 1-29.

Green, E. 2013. 'Research in the New Christian Academies: Perspectives from Bourdieu'. In Social Theory and Education Research Understanding Foucault, Habermas, Bourdieu and Derrida, edited by Mark Murphy. London; New York: Routledge.

Greenhow, Christine, Beth Robelia, and Joan E. Hughes. 2009. 'Learning, Teaching, and Scholarship in a Digital Age Web 2.0 and Classroom Research: What Path Should We Take Now?' Educational Researcher 38 (4): 246-59.

Hemmi, A., S. Bayne, and R. Land. 2009. 'The Appropriation and Repurposing of Social Technologies in Higher Education'. Journal of Computer Assisted Learning 25 (1): 1930.

Holligan, Christopher. 2011. 'Feudalism and Academia: UK Academics' Accounts of Research Culture'. International Journal of Qualitative Studies in Education 24 (1): 55-75.

Jarrett, Kylie. 2008. 'Interactivity Is Evil! A Critical Investigation of Web 2.0'. First Monday 13 (3). http://frodo.lib.uic.edu/ojsjournals/index.php/fm/article/view/2140/1947. 
This is an accepted author manuscript" (AAM) (also known as the "author post-print")

Jenkins, Richard. 2002. Pierre Bourdieu. 2nd ed. Routledge.

Kemp, B, and C Jones. 2007 'Academic Use of Digital Resources: Disciplinary Differences and the Issue of Progression Revisited'. Educational Technology \& Society 10 (1): 52-60.

King, Anthony. 2000. 'Thinking with Bourdieu Against Bourdieu: A "Practical" Critique of the Habitus'. Sociological Theory 18 (3): 417-33. doi:10.1111/0735-2751.00109.

Laakso, Mikael, Patrik Welling, Helena Bukvova, Linus Nyman, Bo-Christer Björk, and Turid Hedlund. 2011. 'The Development of Open Access Journal Publishing from 1993 to 2009'. PLOS ONE 6 (6): e20961.

Lee, Frederic. 2007. 'The Research Assessment Exercise, the State and the Dominance of Mainstream Economics in British Universities'. Cambridge Journal of Economics 31 (2): 309-25. doi:10.1093/cje/bel021.

Lingard, Bob., Rawolle, Shaun., 2004. Mediatizing educational policy: the journalistic field, science policy, and cross-field effects. Journal of Education Policy 19, 361-380.

Lucas, Lisa. 2006. The Research Game in Academic Life. McGraw-Hill International.

Mason, Robin, and Frank Rennie. 2007. 'Using Web 2.0 for Learning in the Community'. The Internet and Higher Education 10 (3): 196-203. 
This is an accepted author manuscript" (AAM) (also known as the "author post-print")

---. 2008. E-Learning and Social Networking Handbook: Resources for Higher Education.

Taylor \& Francis.

Mcloughlin, Catherine, and Mark J W Lee. 2007. 'Social Software and Participatory Learning : Pedagogical Choices with Technology Affordances in the Web 2 . 0 Era Introduction : Social Trends and Challenges'. Current 2007 (1): 664-75.

Nash, Roy. 1999. 'Bourdieu, "Habitus", and Educational Research: Is It All Worth the Candle?' British Journal of Sociology of Education 20 (2): 175-87.

Naughton, John. 2012. From Gutenberg to Zuckerberg: What You Really Need to Know About the Internet. Quercus.

Nichols, Stephen. 2009. 'Time to Change Our Thinking: Dismantling the Silo Model of Digital Scholarship'. Ariadne (58). http://www.ariadne.ac.uk/issue58/nichols/.

Northcott, Deryl, and Simon Linacre. 2010. 'Producing Spaces for Academic Discourse: The Impact of Research Assessment Exercises and Journal Quality Rankings'. Australian Accounting Review 20 (1): 38-54.

Patton, Michael Quinn. 1990. Qualitative Evaluation and Research Methods. Second Edition. Sage Publications, Inc. 
This is an accepted author manuscript" (AAM) (also known as the "author post-print")

Pearce, Nick, Martin Weller, Eileen Scanlon, and Sam Kinsley. 2011. ‘Digital Scholarship Considered : How New Technologies Could Transform Academic Work.' Article. March 11. http://dro.dur.ac.uk/8072/.

- - - 2012. 'Digital Scholarship Considered: How New Technologies Could Transform Academic Work'. In Education 16 (1).

http://ineducation.couros.ca/index.php/ineducation/article/view/44.

Rawolle, Shaun, 2005. Cross-field effects and temporary social fields: a case study of the mediatization of recent Australian knowledge economy policies. Journal of Education Policy 20, 705-724.

Rawolle, Shaun., \& Lingard, B. (2008). The sociology of Pierre Bourdieu and researching education policy. Journal of Education Policy, 23(6), 729-741.

Reay, Diane. 1995. “'They Employ Cleaners to Do That": Habitus in the Primary Classroom'. British Journal of Sociology of Education 16 (3): 353-71..

- - - 2004. “'It"s All Becoming a Habitus': Beyond the Habitual Use of Habitus in Educational Research'. British Journal of Sociology of Education 25 (4): 431-44.

Rhoades, Emily B., Curtis R. Friedel, and A. Christian Morgan. 2009. 'Can Web 2.0 Improve Our Collaboration?' Techniques: Connecting Education and Careers 84 (1): 24-27. 
This is an accepted author manuscript" (AAM) (also known as the "author post-print")

Riessman, Catherine. 2007. Narrative Methods for the Human Sciences. Sage Publications, Inc.

Samuel, Chris. 2010. 'Normalization as Symbolic Violence: Collective Identities and the Ethics of Resistance'. In 'We Demand': History/Sex/Activism In Canada. http://ocs.sfu.ca/history/index.php/wedemand/2011/paper/view/85.

Schwab, Joseph J. 1960. 'Inquiry, the Science Teacher, and the Educator'. The School Review 68 (2): 176-95.

Smith, Simon, Vicky Ward, and Allan House. 2011. "Impact" in the Proposals for the UK's Research Excellence Framework: Shifting the Boundaries of Academic Autonomy'. Research Policy 40 (10): 1369-79.

Swan, Alma. 2010. 'The Open Access Citation Advantage: Studies and Results to Date'. Monograph. February. http://eprints.soton.ac.uk/268516/.

Talib, Ameen Ali. 1999. 'Simulations of the Submission Decision in the Research Assessment Exercise; the "who" and "where" Decision'. Education Economics 7 (1): 39-51.

- - - 2001. 'The Continuing Behavioural Modification of Academics since the 1992 Research Assessment Exercise.' Higher Education Review 33 (3): 30-46. 
This is an accepted author manuscript" (AAM) (also known as the "author post-print")

- - - 2002. 'The Research Assessment Exercise and Motivation: A Note on the Difference in the Impact on the Active Researchers and the Non-Active.' Higher Education Review 34 (2): 51-59.

Thomson. 2008. 'Field'. In Pierre Bourdieu: Key Concepts, edited by Michael Grenfell. Stocksfield [England]: Acumen.

Topp, Libby, Bridget Barker, and Louisa Degenhardt. 2004. 'The External Validity of Results Derived from Ecstasy Users Recruited Using Purposive Sampling Strategies'. Drug and Alcohol Dependence 73 (1): 33-40.

Veletsianos, G. 2012. 'Higher Education Scholars' Participation and Practices on Twitter'. Journal of Computer Assisted Learning 28 (4): 336-49. doi:10.1111/j.13652729.2011.00449.x.

Veletsianos, George. 2010. 'Participatory Scholars and 21st Century Scholarship'. George Veletsianos... a Place to Log Ideas and Thoughts.

http://www.veletsianos.com/2010/04/06/participatory-scholars-scholarshi/.

Veletsianos, George, and Royce Kimmons. 2012. 'Assumptions and Challenges of Open Scholarship'. The International Review of Research in Open and Distance Learning 13 (4): 166-89. 
This is an accepted author manuscript" (AAM) (also known as the "author post-print")

Wacquant, Loic., 2013. Homines in Extremis: What Fighting Scholars Teach Us about Habitus. Body \& Society

Wacquant, Loic., 2014. Putting Habitus in its Place: Rejoinder to the Symposium. Body \& Society $20,118-139$.

Weller, Martin. 2011. The Digital Scholar: How Technology Is Changing Academic Practice. Bloomsbury Publishing PLC.

Weller, Martin, and Terry Anderson. 2013. 'Digital Resilience in Higher Education'. European Journal of Open, Distance and Elearning (EURODL) 2013 (1). http://www.eurodl.org/?p=current \&article=559.

Wellington, Jerry, and Carole J. Torgerson. 2005. 'Writing for Publication: What Counts as a “high Status, Eminent Academic Journal”?' Journal of Further and Higher Education 29 (1): 35-48.

Wenger, Etienne, Richard Arnold McDermott, and William Snyder. 2002. Cultivating Communities of Practice: A Guide to Managing Knowledge. Harvard Business Press.

Whitley, R. (2000). The intellectual and social organization of the sciences. Oxford University Press. 
This is an accepted author manuscript" (AAM) (also known as the "author post-print")

Willets, D. 2011. 'Gareth Roberts Science Policy Lecture | News | BIS'. Speech. October 20. http://www.bis.gov.uk/news/speeches/david-willetts-gareth-roberts-science-policylecture-2011.

Williams, G. 1998. 'Misleading, Unscientific, and Unjust: The United Kingdom's Research Assessment Exercise'. BMJ (Clinical Research Ed.) 316 (7137): 1079-82.

Williams, James F. 2001. 'Leadership Evaluation and Assessment'. Journal of Library Administration 32: 153-76. doi:10.1300/J111v32n03_10.

Xia, Jingfeng. 2010. 'A Longitudinal Study of Scholars Attitudes and Behaviors toward Openaccess Journal Publishing'. Journal of the American Society for Information Science and Technology 61 (3): 615-24. doi:10.1002/asi.21283.

\footnotetext{
${ }^{1}$ Joint Information System Committee

${ }^{2}$ For the purpose of this research the term open access is used to true gold open access publishing, i.e., toll-free academic journals for both the authors and readership

${ }^{3}$ As a response to institutions' strategies to ensure academics published in high rank journals, the Minister for Universities and Science in the UK, David Willetts, came to reassure researchers and institutions that they should not feel obliged to follow and favour the trend of prestigious journals:

The instructions to assessment panels are that they must judge on the basis of quality, quality, quality - not location, location, location. So individual researchers can submit pieces of work that have appeared outside the conventional hierarchy of journals, and I am assured by the people running the REF that they will not be penalised for this' (Willetts, 2011).
} 